\title{
N400 Effects of Semantic Richness can be Modulated by Task Demands
}

\author{
Rocío A. López Zunini ${ }^{\mathrm{ab}}$, Louis Renoult ${ }^{\mathrm{c}}$ and Vanessa Taler ${ }^{\mathrm{ab}}$
}

\begin{abstract}
Affiliations
a University of Ottawa , 75 Laurier Av. East, Ottawa, Ontario, Canada, K1N 6N5

b Bruyère Research Institute, 75 Bruyere St., Ottawa, Ontario, Canada, K1N 5C8

c University of East Anglia, Norwich Research Park, Norwich, United Kingdom, NR4 7TJ
\end{abstract}

Email addresses

Rocío A. López Zunini: rlope056@uottawa.ca

Louis Renoult: L.Renoult@uea.ac.uk

*Vanessa Taler: vtaler@uottawa.ca

*Corresponding Author 


\begin{abstract}
Semantic richness is a multidimensional construct that can be defined as the amount of semantic information associated with a concept. Objective: to investigate neurophysiological correlates of semantic richness information associated with words and its interaction with task demands.

Method: two different dimensions of semantic richness (number of associates and number of semantic neighbors) were investigated using Event-Related Potentials (ERPs) in lexical decision (LDT) and semantic categorization tasks (SCT) using the same stimuli in two groups of participants (24 in each group). Results: the amplitude of the N400 ERP component, which is associated with semantic processing, was smaller for words with a high number of associates $(\mathrm{p}=.003$ at fronto-centro-parietal sites) or semantic neighbors $(\mathrm{p}<.03$ at centro-parietal sites) than for words with a low number of associates or number of semantic neighbors, in the LDT but not the SCT. Conclusions: these results suggest that the effects of semantic richness vary with task demands and may be used in a top-down manner to accommodate the current context.
\end{abstract}

\title{
Keywords
}

Semantic richness, lexical associates, semantic neighbors, N400 


\section{Introduction}

Concepts and their meanings are vital for language comprehension and communication, and yet we still do not fully understand the complex process by which meaning is extracted from words. In recent years, a construct referred to as semantic richness has received considerable attention from language researchers (e.g., Pexman, Siakaluk, \& Yap, 2013). Semantic richness refers to the amount of semantic information that is associated with a given lexical item. A number of behavioral studies have shown that words that are semantically rich (i.e., words that possess relatively more semantic information) are recognized more quickly and accurately than words that possess less semantic information (Buchanan, Westbury, \& Burgess, 2001; Duñabeitia, Aviles, \& Carreiras, 2008; Pexman, Hargreaves, Siakaluk, Bodner, \& Pope, 2008; Yap, Tan, Pexman, \& Hargreaves, 2011).

A classical view of conceptual knowledge holds that concepts are stable and situationally invariant (“conceptual stability”) (Collins \& Loftus, 1975; Fodor, 1975). More specifically, processing a concept involves the activation of a fixed set of properties; this process cannot be modified by task demands and is context-independent. However, recent behavioral studies have found that performance with concepts that are semantically rich can differ according to the demands of the task and can be context-dependent (Pexman et al., 2008; Tousignant \& Pexman, 2012; Yap et al., 2011). For example, a semantic richness variable may yield a facilitatory reaction time effect during lexical decision but not during concrete/abstract semantic categorization (Pexman et al., 2008), or it may yield a facilitatory effect in a semantic categorization task but only when participants respond to the experimental items (i.e. go/nogo semantic categorization) (Siakaluk, Buchanan, \& Westbury, 2003). Such findings support theories assuming that concepts are flexible. According to this perspective, concepts are 
comprised of dynamical properties that can be context-dependent (Hoenig, Sim, Bochev, Herrnberger, \& Kiefer, 2008; Kiefer \& Pulvermuller, 2012). To interpret this perspective within the word recognition literature, Balota and Yap (2006) put forward the notion of a flexible lexical processor, which states that attentional control is directed to language processes (e.g., orthographic, phonological, semantic) that are pertinent to perform a task. Empirical evidence supporting this notion shows that while lexical decision is mainly driven by familiarity and meaning, naming is driven by length, orthographic neighborhood size and spelling-to-sound consistency (Balota et al., 2004), suggesting that participants engaged different language processes depending on the demands of the task.

The notion that concepts are flexible implies that semantic richness effects observed in only one type of task cannot provide a full picture about the nature of semantic representations. Semantic richness dimensions that are important in one task may not be important in others. Depending on task demands, some dimensions might be emphasized at the expense of others, suggesting that meaning is dynamically shaped.

\section{Multidimensionality of Semantic Richness}

Semantic richness is a construct comprised of several dimensions (Yap, Pexman, Wellsby, Hargreaves, \& Huff, 2012). These dimensions have been shown to influence word recognition and language processing, and include: number of features, number of related senses, number of associates, number of semantic neighbors, and body-object interaction, amongst others (Buchanan et al., 2001; Duñabeitia et al., 2008; Pexman, Holyk, \& Monfils, 2003; Pexman, Lupker, \& Hino, 2002; Siakaluk, Pexman, Aguilera, Owen, \& Sears, 2008; Siakaluk, Pexman, Sears, et al., 2008). In this study, we chose to investigate two different dimensions thought to 
reflect distinct semantic properties of a concept (Buchanan et al., 2001; Locker, Simpson, \& Yates, 2003; Mirman \& Magnuson, 2008): Number of Associates (NA) and Number of Semantic Neighbors (NSN).

NA is defined as the number of first associates produced in a free association task (Nelson, McEvoy, \& Schreiber, 1998). Nelson and colleagues quantified NA in a large norming study where they asked participants to provide the first word that came to mind after being given a target word. Later, the number of responses was counted per target word (excluding responses given only by a single participant). Thus, NA is considered a measure of semantic neighborhood density: words with many associates reside in a dense associative neighborhood, while words with few associates reside in a sparse neighborhood.

NA has been extensively studied in the word recall and visual word recognition domains. Words with few associates are recalled better than words with many associates in cued recall tasks (Nelson, Schreiber, \& McEvoy, 1992). In addition, an associate that is strongly activated by the target is a more effective cue during cued recall tasks than a weakly activated associate (Pexman et al., 2002). In lexical decision tasks, words with many associates are processed faster than words with few associates (Balota, Cortese, Sergent-Marshall, Spieler, \& Yap, 2004; Buchanan et al., 2001; Dunabeitia et al., 2008; Locker et al., 2003; Yates, Locker, \& Simpson, 2003). However, a study that used hierarchical regression analyses on lexical and several semantic richness variables found that NA effects did not predict performance in lexical decision or semantic categorization tasks after accounting for other semantic variables (Yap et al., 2011). Thus, it is not yet clear if NA is modulated by task demands.

The dimension NSN can be defined according to the language-based model: words that co-occur in large corpora of text in similar contexts cluster together and are thus considered 
semantic neighbors (Burgess \& Lund, 2000; Landauer \& Dumais, 1997; Lund \& Burgess, 1996). One way to quantify this variable is by measuring the number of global neighbors of a word within a radius of semantic space (e.g., words' co-ocurrence within a radius of 10 words) (Durda \& Buchanan, 2008). Thus, words with high NSN share lexical contexts with many other words, whereas the opposite applies for words with low NSN. Behavioral studies that quantified semantic neighborhood according to this model have found that words with large neighborhoods are processed more quickly and accurately than words with small neighborhoods. This facilitatory effect has been found in lexical decision (Buchanan et al., 2001; Pexman et al., 2008; Yap et al., 2012; Yap et al., 2011) and naming tasks (Buchanan et al., 2001). However, the effects in semantic categorization tasks are not consistent. Mirman and Magnuson (2008) found that some measures of semantic neighborhood were positively correlated with reaction time and accuracy in a living/non-living semantic categorization task (Mirman \& Magnuson, 2008), while Siakaluk et al. (2003) found an effect only when participants had to respond to the target item (go/nogo semantic categorization) but not if they had to response with a yes/no answer (Siakaluk et al., 2003). Finally, regression analyses showed that NSN did not predict reaction times in semantic categorization tasks when other variables were controlled for (Pexman et al., 2008; Yap et al., 2012; Yap et al., 2011). It thus appears that NSN could be modulated by task demands, as effects have been reported in lexical decision and naming tasks but less consistently in semantic categorization tasks.

\section{Neural Dynamics Associated with Semantic Richness}

A useful technique for investigating the time course of semantic richness effects in language processing is the use of event-related potentials (ERPs). ERPs are derived from 
electroencephalograms (EEG) and provide a millisecond-by-millisecond measure of cortical activity, thus allowing discrimination of different stages of word processing in a way that is not possible with a simple measure of response time.

Although several ERP studies have investigated the influence of semantic richness on visual word recognition (Amsel, 2011; Amsel \& Cree, 2013; Kounios et al., 2009; Laszlo \& Federmeier, 2012; Muller, Duñabeitia, \& Carreiras, 2010; Rabovsky, Sommer, \& Abdel Rahman, 2012; Taler, Kousaie, \& López Zunini, 2013), none has systematically investigated how the neural dynamics of semantic richness interact with task demands. The main ERP component investigated has been the $\mathrm{N} 400$, which is a negative-going waveform peaking at about 400 milliseconds post-stimulus onset that is consistently modulated by semantic processing (Kutas \& Federmeier, 2011).

Number of Features (NF) refers to the number of attributes or properties associated with a concept (McRae, Cree, Seidenberg, \& McNorgan, 2005). The number of semantic features associated with a given concept is typically identified in studies where participants are asked to list features or attributes associated with a word (e.g., for the word "dog" these might be "has four legs", "barks", "has fur"). ERP studies focusing on this variable have reported inconsistent results. Some studies found smaller N400 amplitudes for high NF than for low NF words (Amsel \& Cree, 2013; Kounios et al., 2009), while others found the opposite effect (Amsel, 2011; Rabovsky et al., 2012). The inconsistency in results may be explained in part by the nature of the tasks used in these studies. Participants in Kounios et al. (2009) performed a semantic relatedness task, where they had to decide whether word pairs where related or not. Participants in Amsel \& Cree's study (2013) performed a concrete/abstract semantic categorization task, while participants in Amsel (2011), silently read words and were asked to judge their 
imageability after the word was presented. Finally, participants in Rabovsky et al.'s study (2012) performed a lexical decision task. Thus, it appears that discrepancies reported for the neural correlates of NF could be due to differences in task demands. The semantic relatedness and categorization tasks in Kounios et al. (2009) and Amsel \& Cree (2013) may rely more on semantic access than the silent reading and lexical decision tasks in Amsel (2011), and Rabovsky et al. (2012). More reliance on semantic information access in some tasks relative to others may account for distinct patterns of N400 effects.

ERP studies investigating NA have also reported inconsistent results. Muller et al. (2010) and Laszlo \& Federmeier (2011) found larger N400 amplitudes in words with high NA than words with low NA. In contrast, Rabovsky et al. (2012) did not observe any difference in high vs low NA words. This discrepancy may again be explained by variations in task demands. Participants in Rabovksy et al. and Muller et al. performed a lexical decision task, while participants in Laszlo \& Federmeier's study performed a substantive behavioral task (stimuli consisted of words, pseudowords, illegal strings and acronyms) where participants had to decide whether they saw a proper noun or not.

Finally, NSN is a dimension that has been investigated in a number of behavioral studies (Buchanan et al., 2001; Pexman et al., 2008; Yap et al., 2012; Yap et al., 2011) and there is evidence that its effects are modulated by task demands (Pexman et al., 2008; Yap et al., 2012; Yap et al., 2011). However, the neural dynamics of NSN have not yet been investigated. This will be the first study to examine its ERP correlates and compare its effects in two different language tasks.

The present study tests the hypothesis that N400 semantic richness effects are modulated by task demands. We investigated this hypothesis using two different semantic richness 
dimensions thought to capture semantic relatedness, NA and NSN, in two different tasks, a lexical decision task (LDT) and a semantic categorization task (SCT). In an LDT, participants may rely more on familiarity-based information (e.g., word frequency) to discriminate a word from a pseudo-word (Balota \& Chumbley, 1984; Balota, Cortese, Sergent-Marshall, Spieler, \& Yap, 2004; Yap \& Balota, 2007). In contrast, in an SCT, participants may have to determine the specific meaning of a word or at least need more access to semantic information than in a LDT in order to make a decision. In order to systematically compare NA and NSN effects, the word stimuli in the LDT and SCT were identical.

Given our previous semantic richness N400 results during lexical decision we hypothesized that words with high NA and high NSN would yield smaller N400s than low NA and low NSN words, respectively. In addition, given previous evidence about semantic richness dynamics with task demands (Yap et al., 2011), we hypothesized that the N400 effect would be larger during the SCT than during the LDT because more semantic information may be accessed during the SCT.

\section{Methods}

\section{Participants}

Participants were 48 (34 females) right handed English monolingual young adults recruited through printed ads from the University of Ottawa and through social media ads from the community. Their mean age was $21.14(+/-2.73)$ and they had $15.31(+/-1.61)$ years of education at the time of testing. Participants were randomly assigned to one of two groups $(n=24$ per group): one group performed two LDTs and the other performed two SCTs. Across groups, participants did not differ significantly in age or education ( $p>0.1$ in both cases). All 
participants completed a self-report health and history questionnaire to confirm they were in good health, had no neurological or psychiatric history, and were not taking any medication known to affect cognitive function. Participants signed a consent form approved by the ethics committee at Bruyère Research Institute and the University of Ottawa. They were compensated $\$ 10$ an hour for their participation.

\section{Testing Procedure}

Participants were seated in a chair at about $60 \mathrm{~cm}$ from a computer monitor while their EEG was being recorded. Depending on the group to which they were assigned, they were asked to perform two different lexical decision tasks or two different living/non-living semantic categorization tasks, where stimuli varied along either the NA or NSN dimension. The order each task was performed was counterbalanced among participants. In order to avoid practice or ERP repetition effects, the stimuli were different for each of the two dimensions (i.e., words and pseudowords were not repeated). Testing took approximately 1.5 hours including set-up of the EEG cap.

\section{Experimental Tasks}

Experimental tasks were programmed and presented with E-prime 2.0 software (Psychology Software Tools, Pittsburg, PA, USA). Tasks were presented on a Dell OptiPlex 780 desktop computer with Windows XP Professional operating system, an Intel Core 2 Duo processor and a 20', screen.

Lexical Decision Task. In the LDT, a fixation cross (+) was presented for a randomly varied inter-stimulus interval between 800 and $1500 \mathrm{~ms}$ at the center of the screen. Next a stimulus 
(either a word or a pseudoword) was presented in white 18 point Courier New font on a black background for $2000 \mathrm{~ms}$ or until the participant made a response. Participants were instructed to indicate whether each stimulus was a word or not as quickly and as accurately as possible by pressing one of two keys on the keyboard. Response buttons were counterbalanced such that half of the participants responded by pressing the " $\mathrm{A}$ " to indicate a word or the " $\mathrm{L}$ " to indicated a pseudoword, while the other half of the participants did the opposite.

Semantic Categorization Task. In the SCT, a fixation cross (+) was presented for a randomly varied inter-stimulus interval between 800 and $1500 \mathrm{~ms}$ at the center of the screen. Next, a stimulus (note that the real-word stimuli are the same set that was used in the LDT) was presented in white 18 point Courier New font on a black background for $2000 \mathrm{~ms}$ or until the participant made a response. Participants were instructed to respond whether each stimulus was a living or a non-living entity by pressing one of two buttons. Response buttons " $\mathrm{A}$ " and "L" were counterbalanced among participants in the same way as in the LDT.

\section{Stimuli}

As previously mentioned, word and pseudo-word stimuli were not repeated between dimensions (i.e., NA and NSN tasks were comprised of different words). However, within each dimension, the stimuli in the LDT and SCT were identical, thus allowing us to systematically compare the effect of a particular dimension of semantic richness across two different tasks.

Each task (LDT or SCT) consisted of a total of 60 words high in semantic richness (high NA or high NSN) and 60 words low in semantic richness (low NA or low NSN), balanced across a number of variables known to influence behavioral performance and N400 amplitude. The variables controlled for included word length, word frequency (as Hyperspace Analogue to 
Language or HAL frequency), orthographic neighborhood density and bigram frequency by position (the English Lexicon Project) (Balota et al., 2007), concreteness, familiarity, and imageability (MRC Psycholinguistic Database) (Coltheart, 1981). NA was determined using the University of South Florida Free Association Norms (Nelson et al., 1998). NSN was determined using the number of global neighbors from the University of Windsor database's Wordmine2 (Durda \& Buchanan, 2006).

We also controlled for other dimensions of semantic richness where data were available. For all tasks, we controlled for number of semantic features (McRae et al., 2005) and Body-Object Interaction ratings (Bennett, Burnett, Siakaluk, \& Pexman, 2011; Tillotson, Siakaluk, \& Pexman, 2008). Furthermore, in the tasks that investigated the NA dimension, number of semantic neighbors (Durda \& Buchanan, 2006) was balanced and in the tasks that investigated the NSN dimension, number of associates was balanced.

For each LDT, an additional 120 pseudowords were generated using the English Lexicon Project (Balota et al., 2007) and were matched to the words in length, orthographic neighborhood density and bigram frequency by position. Finally, because the words were identical for the LDT and SCT tasks, 60 of the words were living entities while the other 60 were non-living entities.

Information on lexical and semantic variables for each experiment is provided in Tables 1 and 2.

-Insert Table 1 here-

Insert Table 2 here

\section{EEG Recording}


The continuous EEG was recorded using a commercially available nylon cap with 32 tin electrodes (Electro-Cap International Inc., Eaton, OH, USA) placed according to the international 10-20 system of electrode placement. A cephalic site was used as ground and linked ears were used as the reference. Four additional electrodes were placed on the face to record horizontal and vertical eye movements. The horizontal electro-oculogram was recorded from electrodes placed at the outer canthus of each eye and the vertical electro-oculogram from electrodes placed above and below the left eye. The EEG was amplified with NeuroScan NuAmps (NeuroScan, El Paso, TX, USA), sampling rate was $500 \mathrm{~Hz}$ in a DC to $100 \mathrm{~Hz}$ bandwith and impedances were kept below $5 \Omega$.

EEG data was processed offline using Brain Vision Analyzer 2.1 (Brain Products, GmbH, Munich, Germany). A low pass $20 \mathrm{~Hz}$ filter was applied and Independent Component Analysis (Makeig, Bell, Jung, \& Sejnowski, 1996) was used to identify eye movements and blinks that were statistically independent of the EEG activity. Next, the continuous EEG was segmented into discrete $1100 \mathrm{~ms}$ epochs starting $100 \mathrm{~ms}$ before the onset of the stimulus. The 100 pre-stimulus period served as a zero voltage baseline period and epochs were baseline corrected. Any epochs containing EEG activity exceeding $\pm 100 \mu \mathrm{V}$ on the electrodes of interest were rejected from averaging.

Epochs were sorted and averaged based on stimulus condition of the experimental tasks (i.e., high NA and low NA; high NSN and low NSN). Table 3 illustrates how stimuli were averaged. Only correct responses were included in the averages and all averages contained a minimum of 30 trials. 


\section{Statistical Analyses}

All data was analyzed with the Statistical Package for the Social Sciences v. 20 (SPSS), (IBM, Armonk, NY, USA).

Behavioral Performance. Trials with reaction times (RT) exceeding \pm 2.5 standard deviations from the mean were excluded as outliers. In the NA experiment, In the LDT, $2.7 \%$ trials were excluded as outliers while $2.3 \%$ were excluded in the SCT. In the NSN experiment, In the LDT, $2.7 \%$ of trials were excluded as outliers while $2.6 \%$ were excluded in the SCT.

Accuracy and RT were analyzed in two separate 2X2 Mixed ANOVAs with the withinsubject factor Semantic Richness (either high NA, low NA or high NSN, low NSN) and between-subject factor Task (LDT and SCT).

ERP Data. Electrode sites were grouped into 3 regions of interest (ROIs) that included 5 electrodes each: left lateral (F3, FC3, C3, CP3, P3), midline (Fz, FCz, Cz, CPz, Pz), and right lateral (F4, FC4, C4, CP4, P4). Mean amplitudes from 350 to $550 \mathrm{~ms}$ post-stimulus were chosen for analyses. For each dimension (NA or NSN) a mixed ANOVA was conducted with the following within-subject factors: Semantic Richness (2 levels), Electrode (5 levels), ROI (3 levels) and the between-subject factor Task (LDT vs SCT). Interactions involving the factor Task were decomposed with repeated measures ANOVAs performed for each task with the factors: Semantic Richness, Electrode and ROI. When interactions were significant within a task, additional post-hoc tests with Fisher's Least Significance Difference pairwise comparisons were carried. A Greenhouse-Geisser correction procedure was used for all ERP analyses when sphericity was violated (Geisser \& Greenhouse, 1958). 


\section{Results}

\section{NA Results}

Three participants from the LDT and three from the SCT group were excluded from all analyses due to noisy EEG data. Thus, there was a final sample of 21 participants in each group.

Behavioral Results. ANOVA analyses on reaction time and accuracy did not reveal a main effect of NA nor any interaction involving this factor ( $p>.38$ all tests). Refer to Table 4 for mean accuracy and reaction times for each task.

-Insert Table 4 here

ERP Results. The initial mixed ANOVA revealed an interaction of NA and Task $\left(\mathrm{F}(1,40)=5.37, \mathrm{p}=.03, \eta_{\mathrm{p}}^{2}=.12\right)$, and a main effect of $\mathrm{NA}\left(\mathrm{F}(1,40)=5.31, \mathrm{p}=.03, \eta_{\mathrm{p}}^{2}=.12\right)$. In order to decompose the interaction, post-hoc analysis were carried for each task separately.

Results for the LDT revealed a main effect of NA, F(1,20)=11.80, $p=.003, \eta^{2}=.37$ ) but no interaction with other factors. Low NA words were associated with greater N400 amplitudes than high NA words (see Figure 1). This effect had a central scalp distribution with local maxima at right posterior and frontal sites (see Figure 2), but the interactions between NA, ROI and electrode factors were not significant.

There were no main effects of NA, nor interactions with any other factors in the SCT (p>.27 for all tests). See Figure 1 for grand average waveforms and Figure 2 for topographic distribution of the NA effect in the LDT task. Table 5 displays mean amplitudes at midline electrodes in both tasks. 
-Insert Table 5 here

\section{NSN Results}

Due to noisy EEG data, one participant was excluded from each group yielding a final sample size of 23 participants in each group.

Behavioral Results. Reaction time analyses did not reveal a significant main effect of NSN $(\mathrm{p}=.42)$, nor an interaction between NSN and Task $(\mathrm{F}(1,44)=1.90, \mathrm{p}=.17)$. Similar results were obtained for Accuracy analyses (p>.06 for all tests). Results are summarized in Table 6. -Insert Table 6 here

ERP Results. The initial mixed ANOVA revealed a significant interaction of NSN and Electrode $\left(\mathrm{F}(4,176)=8.13, \mathrm{p}=.002, \mathrm{\eta}^{2} \mathrm{p}=.16\right)$ and a 4-way interaction of NSN, Task, ROI and Electrode approaching significance $\left(\mathrm{F}(8,352)=2.11, \mathrm{p}=.06, \mathrm{\eta}_{\mathrm{p}}^{2}=.05\right)$. Thus, ANOVAS were carried for each task separately.

In the LDT, results revealed an interaction of NSN and Electrode $(F(4,88)=3.65, p=.05$, $\left.\eta_{\mathrm{p}}^{2}=.14\right)$. Post-hoc LSD comparisons revealed that low NSN words were associated with greater N400 amplitudes than were high NSN words at electrodes $\mathrm{C} 3, \mathrm{Cz}, \mathrm{C} 4\left(\mathrm{p}=.03, \eta_{\mathrm{p}}^{2}=.20\right), \mathrm{CP} 3$, $\mathrm{CPz}, \mathrm{CP} 4\left(\mathrm{p}=.02, \eta_{\mathrm{p}}^{2}=.22\right)$, and P3, Pz, P4 (p=.01, $\left.\eta^{2}=.27\right)$ (See Figure 3). This effect had a centro-posterior scalp distribution with local maxima at right posterior sites (see Figure 4).

Insert Figure 3 here Insert Figure 4 here

Analyses of the SCT also revealed an interaction of NSN with Electrode $(F(4,88)=5.85, \mathrm{p}=.004$, $\left.\eta_{\mathrm{p}}^{2}=.21\right)$. However, post-hoc LSD comparisons revealed no significant differences between high 
and low NSN words $(\mathrm{p}=.13)$. Table 7 displays mean amplitudes at midline electrodes in both tasks.

-Insert Table 7 here-

\section{Discussion}

In this study, we investigated the neural correlates of semantic richness and its interaction with task demands. We hypothesized that the N400 effect associated with semantic richness is modulated by task demands. Further, we hypothesized that high NA and high NSN words would yield smaller N400 amplitudes than low NA or low NSN words during both LDT and SCT. Finally, we expected that the N400 effect would be larger in the SCT than the LDT because SCTs are thought to rely more on semantic access than LDTs. Our results are partially consistent with our hypotheses. We found that the N400 effect associated with semantic richness is modulated by task demands. More specifically, our results revealed smaller N400 amplitudes for high NA and high NSN than low NA and low NSN words. However, unexpectedly, this effect was only see in the LDT. No N400 differences between high NA/high NSN and low NA/low NSN words were seen in the SCT.

Semantic priming studies have shown that N400 amplitudes are smaller when target words are preceded by an associated word than by an unrelated word (Kutas \& Federmeier, 2011), suggesting that smaller N400 amplitudes are associated with the ease of processing the meaning of a word. In an LDT, participants have to decide as quickly as they can whether the presented stimulus is a word or not. This decision may be less effortful for words with dense semantic neighborhoods (i.e., high NA or high NSN words) because the many words associated 
with them may also become active within the neural semantic network. Activation of these neighbors may thus allow for more efficient semantic processing: rapid integration of information (semantic associates or neighbors in this study) that results in easier access to word meaning (Holcomb, 1993; Rugg, 1990), resulting in smaller N400 amplitudes. More specifically, the more words associated with or related to a particular target word, the less effortful it is for the brain to make the decision that the presented stimulus is a word.

On the other hand, the null N400 NA and NSN effects in the living/non-living SCT suggests that semantic richness information can be dynamically recruited in a top-down manner depending on task demands. This dynamic process can be interpreted within Balota and Yap's (2006) flexible lexical processor hypothesis, which states that attentional control is directed towards language processes (e.g., orthographic, phonological, semantic) that are pertinent to performing a task. Empirical evidence supporting this notion shows that while lexical decision is mainly driven by familiarity and meaning, naming is driven by length, orthographic neighborhood size and spelling-to-sound consistency (Balota et al., 2004), suggesting that participants engaged different language processes depending on the demands of the task. Similarly, the diverse behavioral effects that semantic richness dimensions exert on visual word recognition can be interpreted within this framework.

Within the semantic richness literature, much of the empirical evidence supporting the flexible lexical processor framework comes from behavioral studies (e.g., Yap et al., 2012; Yap et al., 2011). For example, words with many semantic neighbors are recognized more quickly than words with few neighbors in LDT, while this variable does not have an effect in certain types of SCTs. In contrast, words with a high number of features are recognized faster than words with a low number of features in both LDT and SCT (Pexman et al., 2008; Yap et al., 
2012). Our study provides neurophysiological evidence consistent with the flexible lexical processor framework: different neurophysiological profiles were observed (in the NA and NSN experiments) during performance of two different language tasks, even though word stimuli in both tasks had identical information available.

Certain associates or semantic neighbors of high NA and high NSN words may be completely irrelevant or even distracting when trying to make a living/non-living decision. Some living high NA items are associated with non-living words (e.g., duck can be associated with feather, rubber, and pond) while some non-living high NA items are associated with living items (e.g., cage can be associated with monkey, bird, and animals). Thus, high NA living items may activate attributes/features associated with non-living items and vice-versa. Such type of information can be detrimental to task performance and thus, NA information may not be actively recruited by the participants, which may result in a null N400 effect. Further studies can investigate this hypothesis by carefully choosing living words that have a large number of living associates (e.g., mammal has 10 living associates and 0 non-living associates) and contrast them with living words that have a large number of non-living associates (e.g., fox has 10 non-living associates and 3 living associates). Similarly, the same contrast could be performed with nonliving words and its associates (e.g., cord has 11 non-living associates and 0 living associates while zoo has 2 non-living associates and 11 living associates). One would expect then, to only find semantic richness effects for living and non-living words that have pertinent information to properly perform a SCT (e.g., mammal or cord but not fox or zoo).

The NSN null effects in the SCT can be also interpreted in a similar vein. A number of researchers consider that measures such as semantic neighborhood size and number of associates measure semantic relatedness (Buchanan et al., 2001; Locker et al., 2003; Mirman \& Magnuson, 
2008) albeit through different approaches (statistical co-ocurrence vs. word association). NSN is a reflection of the semantic associates of a word -that is, words that occur in similar contexts in large corpus of text- and thus, some living items may have semantic neighbors that are nonliving and vice-versa. Thus, similarly to NA, the lack of an N400 effect in a living/non-living SCT may indicate that participants do not actively recruit potentially distracting information. Rather, relevant semantic information for the living/non-living decision, such as number of features, may be recruited in a top-down manner by the semantic neural network. The number of semantic features refers to the properties that belong to a particular concept. These properties are intrinsic to the concept and help define it. Thus, this particular semantic richness dimension may allow for more efficient processing during SCT, resulting in smaller N400 amplitudes for high that for low NF words when making a living/non-living decision (Renoult, López Zunini, \& Taler, in preparation).

Our results also suggest that NA and NSN engage related neural networks, because they yielded similar N400 effects. Given that both are measures of semantic relatedness, albeit operationalized differently, it is perhaps unsurprising to find similar N400 effects. However, the differences in topographic distribution suggest that brain areas responsible for the effect are not identical. In future, our paradigm could be run with fMRI or MEG in order to specify brain activation similarities and differences between the NA and NSN dimensions. In addition, graded effects of both variables could be investigated by manipulating both measures within one particular task to see if the effects are additive

Muller et al. (2010) found larger N400s for high than low NA words in an LDT, while we found the opposite effect. However, in their study, there was a significant difference in imageability ratings $(\mathrm{p}<.001)$ between high and low NA words. ERP studies have found that 
high imageability words elicit a larger N400 than low imageability words (Barber, Otten, Kousta, \& Vigliocco, 2013; Gullick, Mitra, \& Coch, 2013; Welcome, Paivio, McRae, \& Joanisse, 2011; West \& Holcomb, 2000). Thus, it is not possible to conclude with certainty that the N400 effects in Muller et al.'s study were due to NA.

Laszlo and Federmeier (2012) also found that N400 amplitudes were greater for high than low NA words. One difference with our study is that Laszlo and Federmeier's participants performed a word recognition task where they only had to respond to filler items and not to the experimental items (i.e., they had to identify proper names) with the aim of investigating ERP correlates of NA free from any lexical or semantic decision. As previously mentioned, there is behavioral evidence that semantic richness variables are dynamic: they can yield facilitatory effects during some tasks but not others. Thus, it is possible that the N400 effect would present a different profile in passive tasks, where experimental items do not require a response than in active tasks, where experimental items do require a response, such as LDT.

Finally, Rabovsky et al. (2012) found an N400 effect with the NF variable, but not with NA, while carefully controlling for both. Although we also partially controlled for NF (norms were not available for all items), the mean difference between high and low NA words in Rabovsky et al. was nine, while in the present experiment, the mean was almost 15 . Thus, it is possible that their NA high/low manipulation was not large enough to detect an effect.

Finally, the ERP technique becomes valuable when behavioral effects are small or nonexistent, because it allows us to detect differences in processing that are not possible with simple reaction time measures. Although we did not find a significant reaction time advantage in the LDT, we were able to detect smaller N400 for high NA and high NSN than low NA and low NSN words. Furthermore, the lack of an N400 effect in the SCT -despite the task having 
identical word stimuli as the LDT- provided us for the first time with evidence that NA and NSN effects may be dynamically shaped by task demands. Future ERP studies should aim to investigate the simultaneous effect of semantic richness variables across a variety of tasks to disentangle the complex dynamics between semantic richness information and task demands during word meaning extraction. 


\section{References}

Amsel, B. D. (2011). Tracking real-time neural activation of conceptual knowledge using singletrial event-related potentials. Neuropsychologia, 49(5), 970-983. doi:

10.1016/j.neuropsychologia.2011.01.003

Amsel, B. D., \& Cree, G. S. (2013). Semantic richness, concreteness, and object domain: an electrophysiological study. Canadian Journal of Experimental Psychology, 67(2), 117 129. doi: $10.1037 / \mathrm{a} 0029807$

Balota, D. A., \& Chumbley, J. I. (1984). Are lexical decisions a good measure of lexical access? The role of word frequency in the neglected decision stage. Journal of Experimental Psychology. Human Perception and Performance, 10(3), 340-357.

Balota, D. A., Cortese, M. J., Sergent-Marshall, S. D., Spieler, D. H., \& Yap, M. J. (2004). Visual word recognition of single-syllable words. Journal of Experimental Psychology General, 133(2), 283-316. doi: 10.1037/0096-3445.133.2.283

Balota, D. A., \& Yap, M. J. (2006). Attentional control and flexible lexical processing: exploration of the magic moment of word recognition. In S. Andrews (Ed.), From inkmarks to ideas: current issues in lexical processing (pp. 229-258). New York, NY: Psychology Press.

Balota, D. A., Yap, M. J. , Cortese, M. .J. , Hutchison, K. A. , Kessler, B. , Loftis, B. , . . . Treiman, R. (2007). The English Lexicon Project. Behavior Research Methods, 39, 445459.

Barber, H. A., Otten, L. J., Kousta, S. T., \& Vigliocco, G. (2013). Concreteness in word processing: ERP and behavioral effects in a lexical decision task. Brain and Language, 125(1), 47-53. doi: 10.1016/j.bandl.2013.01.005 
Bennett, S. D., Burnett, A. N., Siakaluk, P. D., \& Pexman, P. M. (2011). Imageability and bodyobject interaction ratings for 599 multisyllabic nouns. Behavior Research Methods, 43(4), 1100-1109. doi: 10.3758/s13428-011-0117-5

Buchanan, L., Westbury, C., \& Burgess, C. (2001). Characterizing semantic space: neighborhood effects in word recognition. Psychonomic Bulletin \& Review, 8(3), 531-544.

Burgess, C., \& Lund, K. (2000). Cognitive dynamics: Conceptual and representational change in humans and machines. In E. Dietrich \& A. B. Markman (Eds.), The dynamics of meaning in memory (pp. 117-156). Mahwah, NJ: Erlbaum.

Collins, A. M., \& Loftus, E. F. (1975). A spreading activation theory of semantic processing. Psychological Review, 82, 407-428.

Coltheart, M. (1981). The MRC Psycholinguistic Database. Quarterly Journal of Experimental Psychology 33A, 497-505.

Duñabeitia, J. A., Aviles, A., \& Carreiras, M. (2008). NoA's Ark: influence of the number of associates in visual word recognition. Psychonomic Bulletin \& Review, 15(6), 1072-1077. doi: 10.3758/PBR.15.6.1072

Durda, K., \& Buchanan, L. . (2006). WordMine2 [Online] Available. from http://web2.uwindsor.ca/wordmine

Fodor, J. A. (1975). The language of thought. Cambridge, MA: Harvard University Press.

Geisser, S. , \& Greenhouse, S.W. (1958). An extension of Box's result on the use of F distribution in multivariate analysis. Annals of Mathematical Statistics, 29(3), 885-891.

Gullick, M. M., Mitra, P., \& Coch, D. (2013). Imagining the truth and the moon: an electrophysiological study of abstract and concrete word processing. Psychophysiology, 50(5), 431-440. doi: 10.1111/psyp.12033 
Hoenig, K., Sim, E. J., Bochev, V., Herrnberger, B., \& Kiefer, M. (2008). Conceptual flexibility in the human brain: dynamic recruitment of semantic maps from visual, motor, and motion-related areas. Journal of Cognitive Neuroscience, 20(10), 1799-1814. doi: 10.1162/jocn.2008.20123

Holcomb, P. J. (1993). Semantic priming and stimulus degradation: implications for the role of the N400 in language processing. Psychophysiology, 30(1), 47-61.

Kiefer, M., \& Pulvermuller, F. (2012). Conceptual representations in mind and brain: theoretical developments, current evidence and future directions. Cortex, 48(7), 805-825. doi: 10.1016/j.cortex.2011.04.006

Kounios, J., Green, D. L., Payne, L., Fleck, J. I., Grondin, R., \& McRae, K. (2009). Semantic richness and the activation of concepts in semantic memory: evidence from event-related potentials. Brain Research, 1282, 95-102. doi: 10.1016/j.brainres.2009.05.092

Kutas, M., \& Federmeier, K. D. (2011). Thirty years and counting: finding meaning in the N400 component of the event-related brain potential (ERP). Annual Review of Psychology, 62, 621-647. doi: 10.1146/annurev.psych.093008.131123

Landauer, T. K., \& Dumais, S. T. . (1997). A solution to Plato's problem: The latent semantic analysis theory of acquisition, induction, and representation of knowledge. Psychological Review, 104, 211-240.

Laszlo, S., \& Federmeier, K. D. (2012). The N400 as a snapshot of interactive processing: Evidence from regression analyses of orthographic neighbor and lexical associate effects. Psychophysiology, 48, 176-186. doi: 10.1111/j.1469-8986.2010.01058.x

Locker, L., Jr., Simpson, G. B., \& Yates, M. (2003). Semantic neighborhood effects on the recognition of ambiguous words. Memory \& Cognition, 31(4), 505-515. 
Lund, K., \& Burgess, C. (1996). Producing high-dimensional semantic spaces from lexical cooccurrence. Behavior Research Methods, Instruments, \& Computers, 28(203-208).

Makeig, S., Bell, A. J., Jung, T. P. , \& Sejnowski, T. J. (1996). Independent component analysis of electroencephalographic data. In D. Touretzky, M. Mozer \& M. Hasselmo (Eds.), Advances in neural information processing systems (pp. 145-151). ). Cambridge, MA: MIT press.

McRae, K., Cree, G. S., Seidenberg, M. S., \& McNorgan, C. (2005). Semantic feature production norms for a large set of living and nonliving things. Behavior Research Methods, 37(4), 547-559.

Mirman, D., \& Magnuson, J. S. (2008). Attractor dynamics and semantic neighborhood density: processing is slowed by near neighbors and speeded by distant neighbors. Journal of Experimental Psychology. Learning, Memory and Cognition, 34(1), 65-79. doi: $10.1037 / 0278-7393.34 .1 .65$

Muller, O., Duñabeitia, J. A., \& Carreiras, M. (2010). Orthographic and associative neighborhood density effects: what is shared, what is different? Psychophysiology, 47(3), 455-466. doi: 10.1111/j.1469-8986.2009.00960.x

Nelson, D. L., McEvoy, C. L., \& Schreiber, T. A. (1998). The University of South Florida word association, rhyme, and word fragment norms. from http://www.usf.edu/FreeAssociation/

Nelson, D. L., Schreiber, T. A., \& McEvoy, C. L. (1992). Processing implicit and explicit representations. Psychological Review, 99(2), 322-348.

Pexman, P. M., Hargreaves, I. S., Siakaluk, P. D., Bodner, G. E., \& Pope, J. (2008). There are many ways to be rich: effects of three measures of semantic richness on visual word recognition. Psychonomic Bulletin \& Review, 15(1), 161-167. 
Pexman, P. M., Holyk, G. G., \& Monfils, M. H. (2003). Number-of-features effects and semantic processing. Memory \& Cognition, 31(6), 842-855.

Pexman, P. M., Lupker, S. J., \& Hino, Y. (2002). The impact of feedback semantics in visual word recognition: number-of-features effects in lexical decision and naming tasks. Psychonomic Bulletin Review, 9(3), 542-549.

Rabovsky, M., Sommer, W., \& Abdel Rahman, R. (2012). The time course of semantic richness effects in visual word recognition. Frontiers in Human Neuroscience, 6, 11. doi: 10.3389/fnhum.2012.00011

Renoult, L., López Zunini, R. A., \& Taler, V. (in preparation). Greater effects of semantic richness in explicit than implicit semantic tasks.

Rugg, M. D. (1990). Event-related brain potentials dissociate repetition effects of high- and lowfrequency words. Memory and Cognition, 18(4), 367-379.

Siakaluk, P. D., Buchanan, L., \& Westbury, C. (2003). The effect of semantic distance in yes/no and go/no-go semantic categorization tasks. Memory \& Cognition, 31(1), 100-113.

Siakaluk, P. D., Pexman, P. M., Aguilera, L., Owen, W. J., \& Sears, C. R. (2008). Evidence for the activation of sensorimotor information during visual word recognition: the bodyobject interaction effect. Cognition, 106(1), 433-443. doi: 10.1016/j.cognition.2006.12.011

Siakaluk, P. D., Pexman, P. M., Sears, C. R., Wilson, K., Locheed, K., \& Owen, W. J. (2008). The benefits of sensorimotor knowledge: body-object interaction facilitates semantic processing. Cognitive Science, 32(3), 591-605. doi: 10.1080/03640210802035399 
Taler, V., Kousaie, S., \& López Zunini, R. (2013). ERP measures of semantic richness: the case of multiple senses. Frontiers in Human Neuroscience, 7, 5. doi: 10.3389/fnhum.2013.00005

Tillotson, S. M., Siakaluk, P. D., \& Pexman, P. M. (2008). Body-object interaction ratings for 1,618 monosyllabic nouns. Behavior Research Methods, 40(4), 1075-1078. doi: 10.3758/BRM.40.4.1075

Tousignant, C., \& Pexman, P. M. (2012). Flexible recruitment of semantic richness: context modulates body-object interaction effects in lexical-semantic processing. Frontiers in Human Neuroscience, 6, 53. doi: 10.3389/fnhum.2012.00053

Welcome, S. E., Paivio, A., McRae, K., \& Joanisse, M. F. (2011). An electrophysiological study of task demands on concreteness effects: evidence for dual coding theory. Experimental Brain Research, 212(3), 347-358. doi: 10.1007/s00221-011-2734-8

West, W. C., \& Holcomb, P. J. (2000). Imaginal, semantic, and surface-level processing of concrete and abstract words: an electrophysiological investigation. Journal of Cognitive Neuroscience, 12(6), 1024-1037.

Yap, M. J., \& Balota, D. A. (2007). Additive and interactive effects on response time distributions in visual word recognition. Journal of Experimental Psychology. Learning, Memory and Cognition, 33(2), 274-296. doi: 10.1037/0278-7393.33.2.274

Yap, M. J., Pexman, P. M., Wellsby, M., Hargreaves, I. S., \& Huff, M. J. (2012). An abundance of riches: cross-task comparisons of semantic richness effects in visual word recognition. Frontiers in Human Neuroscience, 6, 72. doi: 10.3389/fnhum.2012.00072

Yap, M. J., Tan, S. E., Pexman, P. M., \& Hargreaves, I. S. (2011). Is more always better? Effects of semantic richness on lexical decision, speeded pronunciation, and semantic 
classification. Psychonomic Bulletin \& Review, 18(4), 742-750. doi: 10.3758/s13423011-0092-y 
Table 1. NA Stimuli Characteristics

Variables

\begin{tabular}{|c|c|c|}
\hline NA & \multirow{2}{*}{$\begin{array}{c}\text { p- } \\
\text { value }\end{array}$} & \multirow{2}{*}{$\begin{array}{c}\text { Pseudoword } \\
\text { (SD) }\end{array}$} \\
\hline $\operatorname{High}(S D)$ & & \\
\hline
\end{tabular}

p-value

(NA vs

Pseudoword)

\begin{tabular}{cccccc}
\hline Number of Associates & $18.18(15.61)$ & $3.37(1.30)$ & $<0.001$ & & 0.78 \\
\hline Word Length & $4.85(1.45)$ & $5.28(1.71)$ & 0.14 & $5.12(1.57)$ & 0.81 \\
\hline Frequency (log HAL) & $8.41(1.11)$ & $8.20(1.18)$ & 0.30 & & 0.40 \\
\hline $\begin{array}{c}\text { Orthographic } \\
\text { Neighborhood Density }\end{array}$ & $8.14(6.95)$ & $6.48(7.21)$ & 0.20 & $7.10(6.49)$ & \\
\hline Bigram Frequency & $2416.80(1294.00)$ & $2682.97(1420.00)$ & 0.30 & $2416.40(971.10)$ & \\
\hline Concreteness & $584.52(43.11)^{\mathrm{a}}$ & $582.35(39.41)^{\mathrm{b}}$ & 0.80 & & \\
\hline Familiarity & $510.31(51.68)^{\mathrm{c}}$ & $508.72(40.62)^{\mathrm{b}}$ & 0.87 & \\
\hline Imageability & $579.39(48.74)^{\mathrm{c}}$ & $574.00(48.40)^{\mathrm{b}}$ & 0.60 & & \\
\hline Number of Features & $14.34(4.34)^{\mathrm{d}}$ & $12.78(4.44)^{\mathrm{e}}$ & 0.22 & & \\
\hline $\begin{array}{c}\text { Number of Semantic } \\
\text { Neighbors }\end{array}$ & $2.23(2.16)$ & $2.72(5.06)$ & 0.50 & & \\
\hline $\begin{array}{c}\text { Body-Object } \\
\text { Interaction }\end{array}$ & $4.86(0.83)^{\mathrm{f}}$ & $4.56(1.00)^{\mathrm{g}}$ & 0.20 & &
\end{tabular}

$a=$ available for 48 items, $b=$ available for 43 items, $c=$ available for 49 items, $d=$ available for 22 items, e=available for 27 items, $\mathrm{f}=$ available for 40 items, $\mathrm{g}=$ available for 25 items 
Table 2. NSN Stimuli Characteristics

\begin{tabular}{cccccc}
\multirow{2}{*}{ Variables } & \multicolumn{2}{c}{ NSN } & p-value & $\begin{array}{c}\text { Pseudoword } \\
\text { (SD) }\end{array}$ & $\begin{array}{c}\text { p-value (NA vs } \\
\text { Pseudoword) }\end{array}$ \\
\cline { 2 - 5 } & High(SD) & Low(SD) & & & \\
\hline Number of Semantic Neighbors & $11.67(6.60)$ & $1.90(0.93)$ & $<0.001$ & & 0.97 \\
\hline Word Length & $5.33(1.68)$ & $5.50(0.93)$ & 0.63 & $5.40(1.67)$ & \\
\hline Frequency (log HAL) & $8.30(1.40)$ & $8.12(1.75)$ & 0.78 & & \\
\hline Orthographic Neighborhood Density & $6.27(6.48)$ & $6.10(7.89)$ & 0.90 & $6.18(6.63)$ & 0.90 \\
\hline Bigram Frequency & $2863.40(1509.20)$ & $3085.80(1615.10)$ & 0.44 & $2698.40(1080.22)$ & 0.12 \\
\hline Concreteness & $605.91(20.68)^{\mathrm{a}}$ & $610.82(19.88)^{\mathrm{b}}$ & 0.24 & & \\
\hline Familiarity & $535.22(60.37)^{\mathrm{c}}$ & $520.83(55.58)^{\mathrm{d}}$ & 0.22 & & \\
\hline Imageability & $593.70(29.43)^{\mathrm{a}}$ & $594.22(23.35)^{\mathrm{b}}$ & 0.92 & & \\
\hline Number of Features & $15.25(9.03)^{\mathrm{e}}$ & $14.09(5.67)^{\mathrm{f}}$ & 0.45 & & \\
\hline Number of Associates & $24.50(29.26)^{\mathrm{g}}$ & $19.46(26.33)^{\mathrm{d}}$ & 0.35 & & \\
\hline Body-Object Interaction & $5.16(0.76)^{\mathrm{h}}$ & $4.91(0.85)^{\mathrm{i}}$ & 0.11 & &
\end{tabular}

$\mathrm{a}=$ available for 46 items, $\mathrm{b}=$ available for 51 items, $\mathrm{c}=$ available for 46 items, $\mathrm{d}=$ available for 52 items, e=available for 55 items, $\mathrm{f}=$ =available for 45 items, $\mathrm{g}=$ available for 56 items, $\mathrm{h}=$ available for 48 items, $\mathrm{i}=$ available for 59 items 
Table 3. Illustration of ERP averaging in the LDT and SCT.

\begin{tabular}{ll}
\hline High NA (60 items) & Low NA (60 items) \\
\hline Living rodent & Living beetle \\
\hline Living snake & Living buffalo \\
\hline$\ldots \ldots .$. & $\ldots \ldots .$. \\
\hline$\ldots \ldots .(30$ items $)$ & $\ldots \ldots .(30$ items $)$ \\
\hline Non-living gown & Non-living drill \\
\hline Non-living fork & Non-living zipper \\
\hline$\ldots \ldots \ldots$ & $\ldots \ldots .$. \\
\hline$\ldots \ldots . .(30$ items $)$ & $\ldots \ldots .(30$ items $)$ \\
\hline
\end{tabular}


Table 4. NA Reaction (in ms) and Accuracy (\%)

\begin{tabular}{cccc} 
Task & NA & Reaction Time $($ SD) & Accuracy(SD) \\
\hline \multirow{2}{*}{ LDT } & High & $712.93(91.58)$ & $93.73(5.00)$ \\
\cline { 2 - 4 } & Low & $711.12(101.04)$ & $93.50(5.29)$ \\
\hline \multirow{2}{*}{ SCT } & High & $739.88(86.64)$ & $93.88(3.51)$ \\
\cline { 2 - 4 } & Low & $753.06(77.88)$ & $92.77(3.08)$
\end{tabular}


Table 5. NA N400 Amplitudes (in $\mu \mathrm{V}$ ) at midline electrodes

\begin{tabular}{|c|c|c|c|}
\hline Task & Electrode & NA & $\mathrm{N400(SD)}$ \\
\hline \multirow{10}{*}{ LDT } & \multirow{2}{*}{$\mathrm{Fz}$} & High & $-0.19(2.00)$ \\
\hline & & Low & $-1.07(2.50)$ \\
\hline & \multirow{2}{*}{$\mathrm{FCz}$} & High & $0.04(2.07)$ \\
\hline & & Low & $-0.97(2.18)$ \\
\hline & \multirow{2}{*}{$\mathrm{Cz}$} & High & $0.36(2.30)$ \\
\hline & & Low & $-0.47(2.08)$ \\
\hline & \multirow{2}{*}{$\mathrm{CPz}$} & High & $1.46(2.50)$ \\
\hline & & Low & $0.52(2.24)$ \\
\hline & \multirow{2}{*}{$\mathrm{Pz}$} & High & $2.48(2.74)$ \\
\hline & & Low & $1.60(2.51)$ \\
\hline \multirow{10}{*}{ SCT } & \multirow{2}{*}{$\mathrm{Fz}$} & High & $-1.60(2.60)$ \\
\hline & & Low & $-1.44(3.00)$ \\
\hline & \multirow{2}{*}{$\mathrm{FCz}$} & High & $-1.38(2.70)$ \\
\hline & & Low & $-1.25(3.18)$ \\
\hline & \multirow{2}{*}{$\mathrm{Cz}$} & High & $-0.64(2.64)$ \\
\hline & & Low & $-0.55(3.04)$ \\
\hline & \multirow{2}{*}{$\mathrm{CPz}$} & High & $0.31(2.54)$ \\
\hline & & Low & $0.17(3.22)$ \\
\hline & \multirow{2}{*}{$\mathrm{Pz}$} & High & $1.60(2.82)$ \\
\hline & & Low & $1.40(3.42)$ \\
\hline
\end{tabular}


Table 6. NSN Reaction (in ms) and Accuracy (\%)

\begin{tabular}{|c|c|c|c|}
\hline Task & NSN & $\begin{array}{l}\text { Reaction Time } \\
\text { (SD) }\end{array}$ & Accuracy \%(SD) \\
\hline \multirow{2}{*}{ LDT } & High & $711.50(98.91)$ & $93.11(5.28)$ \\
\hline & Low & $704.62(100.27)$ & $92.10(6.95)$ \\
\hline \multirow{2}{*}{ SCT } & High & $731.05(76.65)$ & $93.62(3.75)$ \\
\hline & Low & 749.72(87.40) & $92.00(3.96)$ \\
\hline
\end{tabular}


Table 7. NSN N400 Amplitudes (in $\mu \mathrm{V}$ ) at midline electrodes

\begin{tabular}{|c|c|c|c|}
\hline Task & Electrode & NSN & N400(SD) \\
\hline \multirow{10}{*}{ LDT } & \multirow{2}{*}{$\mathrm{Fz}$} & High & $-0.51(2.44)$ \\
\hline & & Low & $-0.60(2.25)$ \\
\hline & \multirow{2}{*}{$\mathrm{FCz}$} & High & $-0.16(2.34)$ \\
\hline & & Low & $-0.38(2.33)$ \\
\hline & \multirow{2}{*}{$\mathrm{Cz}$} & High & $0.74(2.52)$ \\
\hline & & Low & $0.19(2.50)$ \\
\hline & \multirow{2}{*}{$\mathrm{CPz}$} & High & $2.04(2.60)$ \\
\hline & & Low & $1.42(2.65)$ \\
\hline & \multirow{2}{*}{$\mathrm{Pz}$} & High & $3.31(2.87)$ \\
\hline & & Low & $2.73(2.84)$ \\
\hline \multirow{10}{*}{ SCT } & \multirow{2}{*}{$\mathrm{Fz}$} & High & $-0.81(3.39)$ \\
\hline & & Low & $-0.77(3.27)$ \\
\hline & \multirow{2}{*}{$\mathrm{FCz}$} & High & $-0.94(3.85)$ \\
\hline & & Low & $-0.73(3.47)$ \\
\hline & \multirow{2}{*}{$\mathrm{Cz}$} & High & $-0.29(4.00)$ \\
\hline & & Low & $-0.57(3.71)$ \\
\hline & \multirow{2}{*}{$\mathrm{CPz}$} & High & $0.57(4.16)$ \\
\hline & & Low & $0.19(3.60)$ \\
\hline & \multirow{2}{*}{$\mathrm{Pz}$} & High & $2.17(4.50)$ \\
\hline & & Low & $1.46(3.73)$ \\
\hline
\end{tabular}




\section{Figure 1. ERPs for the LDT and the SCT Task at the Regions of Interest}

N400 effects can be seen starting at around $350 \mathrm{~ms}$ post-stimulus interval at all ROIs in the LDT task. N400 amplitudes do not significantly differ between high and low NA words in the SCT task. Negative is plotted upwards.

\section{Figure 2. Topographic map of N400 NA effect in LDT Task}

The map was obtained by subtracting the mean voltage of the grand mean ERPs evoked by low NA words from those evoked by high NA words at the $350-550 \mathrm{~ms}$ post-stimulus interval. The effect has a central scalp distribution with local maxima at right posterior and frontal sites.

Figure 3. ERPs for the LDT and the SCT Tasks at the Regions of Interest

N400 effects can be seen starting at around $350 \mathrm{~ms}$ post-stimulus interval at centro-posterior electrodes in the LDT task. N400 amplitudes do not significantly differ between high and low NSN words in the SCT task. Negative is plotted upwards.

\section{Figure 4. Topographic map of N400 NSN effect in LDT Task}

The map was obtained by subtracting the mean voltage of the grand mean ERPs evoked by low NSN words from those evoked by high NSN words at the 350-500 ms post-stimulus interval. This effect had a centro-posterior scalp distribution with local maxima at right posterior sites. 
Figure 1

\section{Lexical Decision Task}

33 non

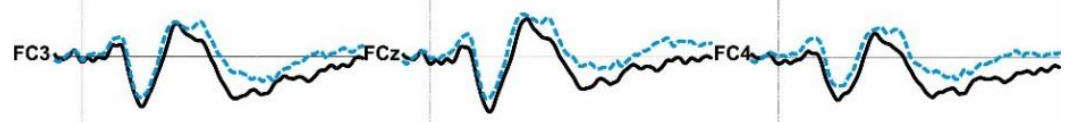

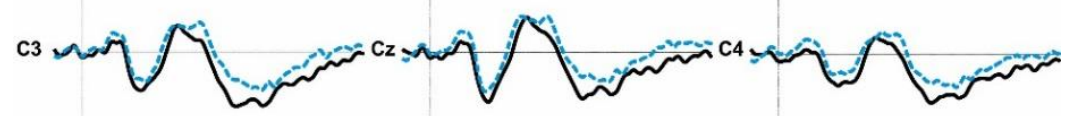

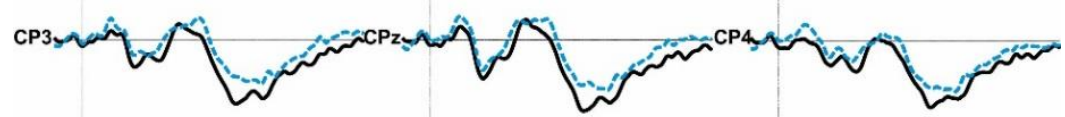

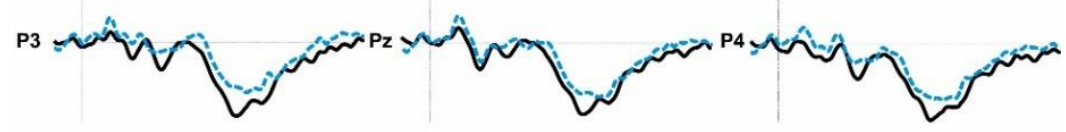

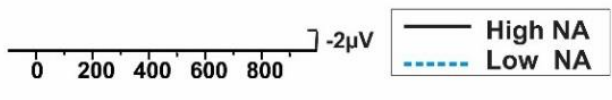

Semantic Categorization Task

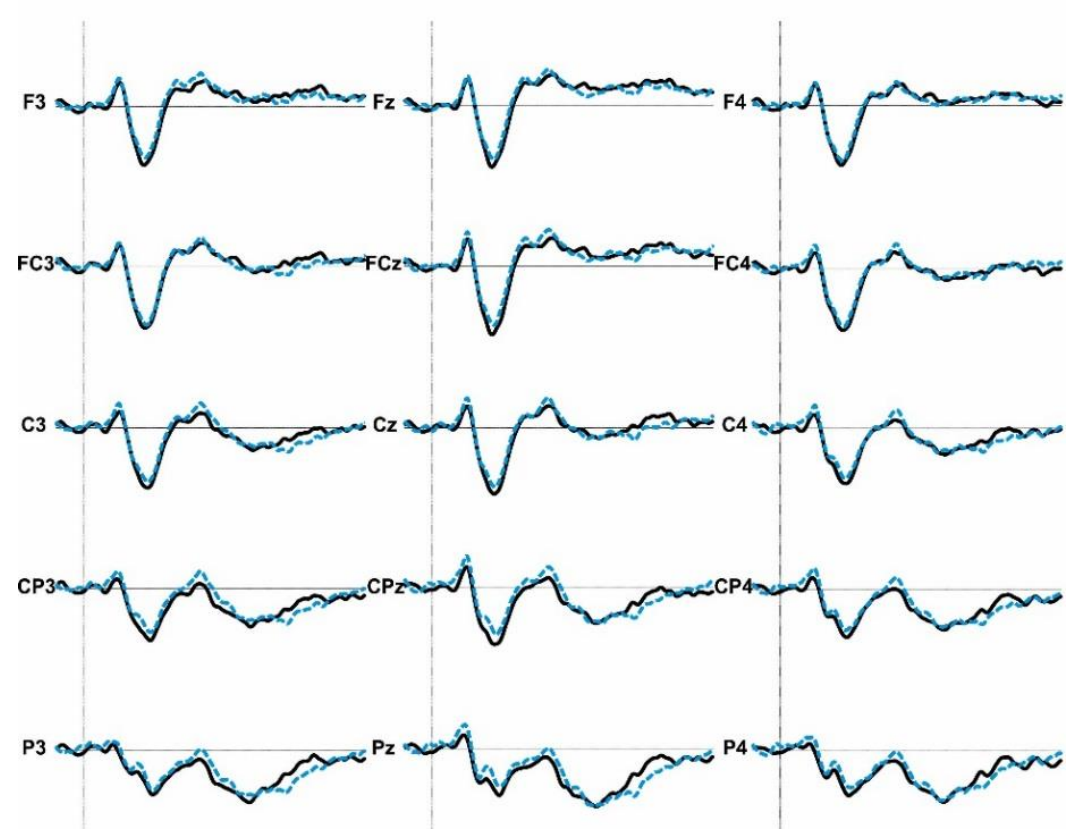


Figure 2

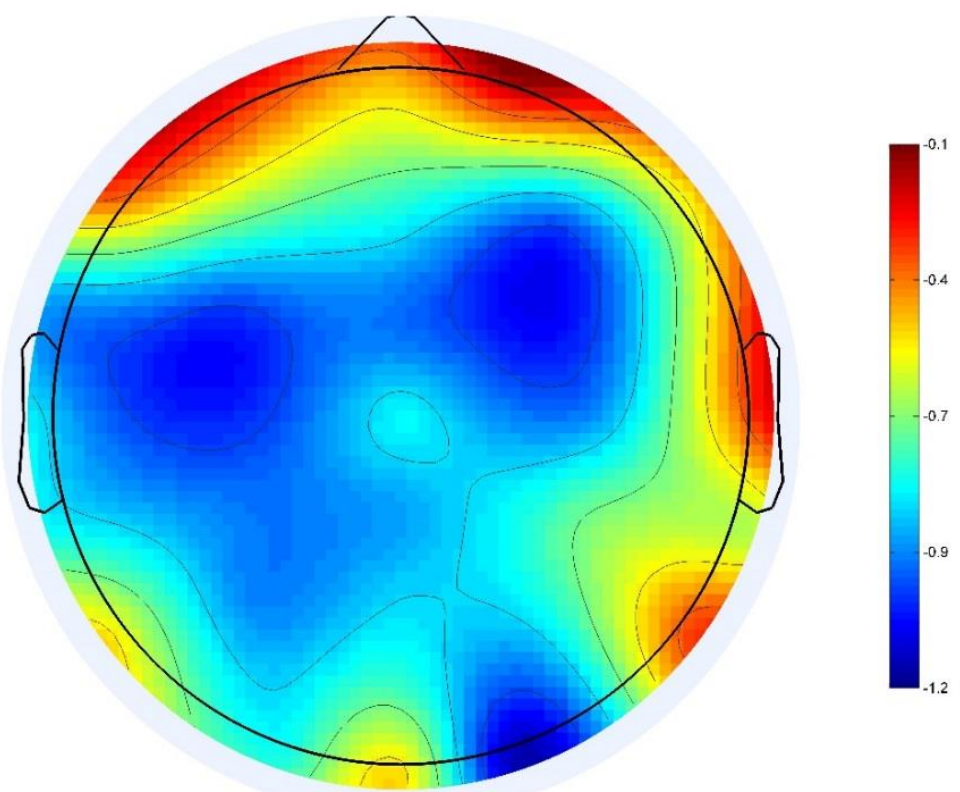


Figure 3

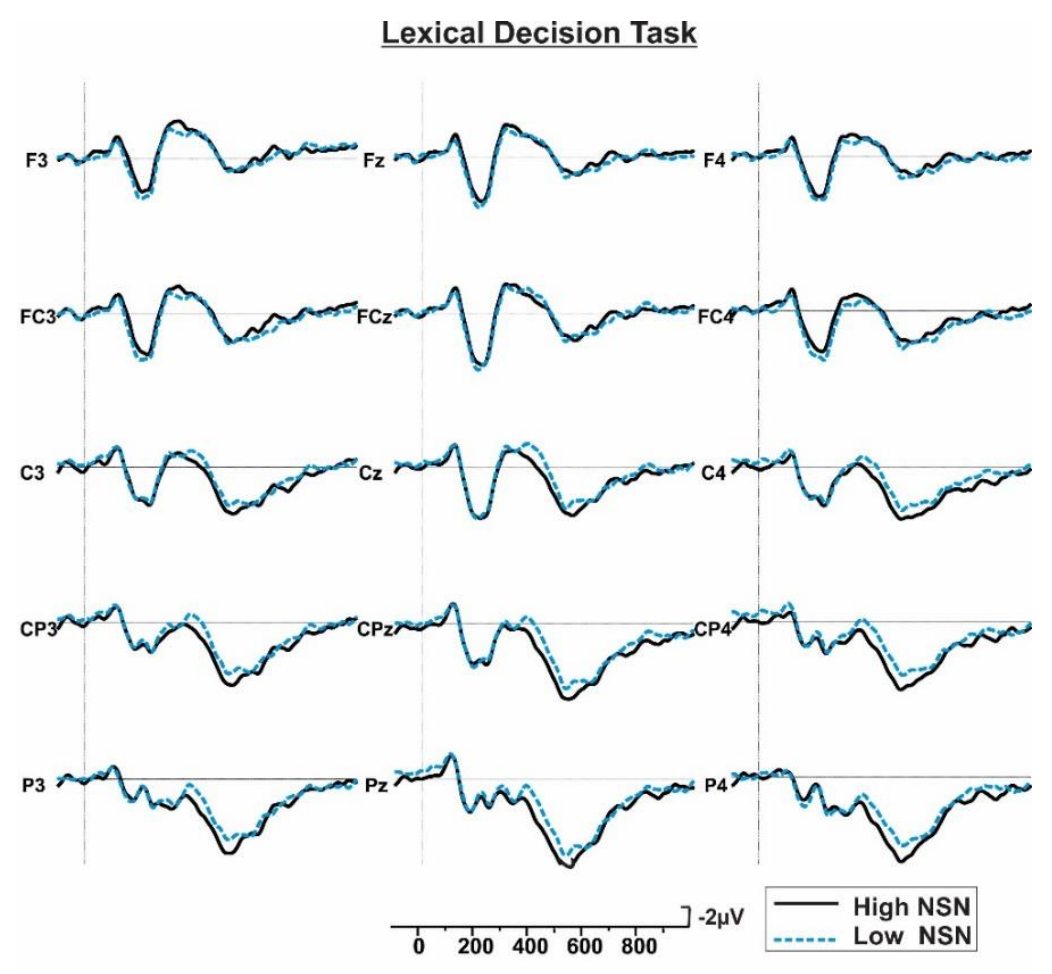

Semantic Categorization Task

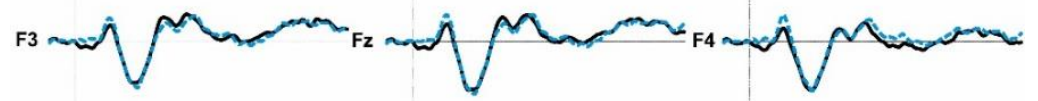

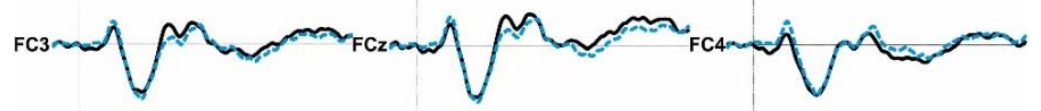

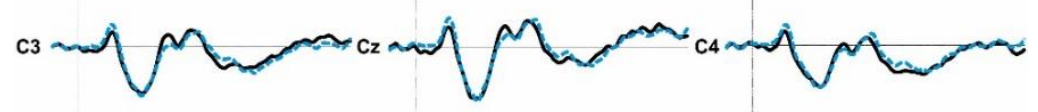

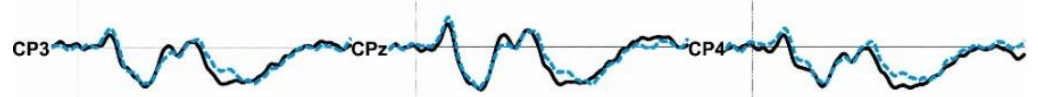

(1) 
Figure 4

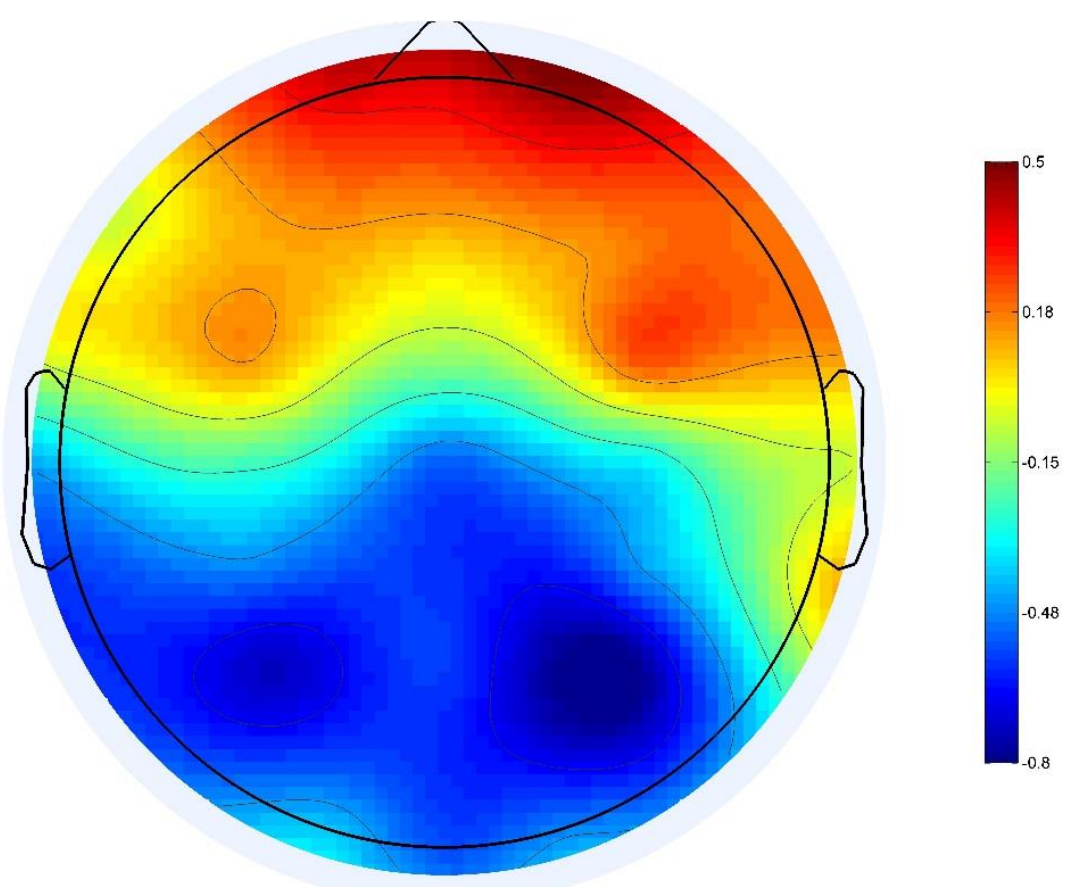


Appendix A. List of words in the NA experiment.

\begin{tabular}{|c|c|c|c|}
\hline \multirow[b]{2}{*}{$\begin{array}{c}\text { NA } \\
\text { Dimension }\end{array}$} & \multirow{2}{*}{ Stimuli } & \multicolumn{2}{|c|}{ Decision Category } \\
\hline & & $\begin{array}{l}\text { Lexical } \\
\text { Decision }\end{array}$ & $\begin{array}{c}\text { Semantic } \\
\text { Categorization }\end{array}$ \\
\hline High & rodent & Word & Living \\
\hline High & oyster & Word & Living \\
\hline High & vegetable & Word & Living \\
\hline High & bunny & Word & Living \\
\hline High & cattle & Word & Living \\
\hline High & insect & Word & Living \\
\hline High & nut & Word & Living \\
\hline High & snake & Word & Living \\
\hline High & bear & Word & Living \\
\hline High & mammal & Word & Living \\
\hline High & fruit & Word & Living \\
\hline High & bug & Word & Living \\
\hline High & cow & Word & Living \\
\hline High & shark & Word & Living \\
\hline High & baby & Word & Living \\
\hline High & bird & Word & Living \\
\hline High & bee & Word & Living \\
\hline High & duck & Word & Living \\
\hline High & worm & Word & Living \\
\hline High & kitten & Word & Living \\
\hline High & fox & Word & Living \\
\hline High & puppy & Word & Living \\
\hline High & seal & Word & Living \\
\hline High & dove & Word & Living \\
\hline High & goose & Word & Living \\
\hline High & ant & Word & Living \\
\hline High & squash & Word & Living \\
\hline High & peach & Word & Living \\
\hline High & crab & Word & Living \\
\hline High & wolf & Word & Living \\
\hline High & cracker & Word & Non-Living \\
\hline High & deodorant & Word & Non-Living \\
\hline High & gown & Word & Non-Living \\
\hline High & barn & Word & Non-Living \\
\hline High & jewel & Word & Non-Living \\
\hline High & lid & Word & Non-Living \\
\hline High & pancakes & Word & Non-Living \\
\hline High & flute & Word & Non-Living \\
\hline High & weapon & Word & Non-Living \\
\hline High & poison & Word & Non-Living \\
\hline
\end{tabular}




\begin{tabular}{|c|c|c|c|}
\hline High & cord & Word & Non-Living \\
\hline High & loan & Word & Non-Living \\
\hline High & hamburger & Word & Non-Living \\
\hline High & spice & Word & Non-Living \\
\hline High & ticket & Word & Non-Living \\
\hline High & $\operatorname{sink}$ & Word & Non-Living \\
\hline High & bowl & Word & Non-Living \\
\hline High & chain & Word & Non-Living \\
\hline High & garbage & Word & Non-Living \\
\hline High & block & Word & Non-Living \\
\hline High & clay & Word & Non-Living \\
\hline High & fork & Word & Non-Living \\
\hline High & whip & Word & Non-Living \\
\hline High & hook & Word & Non-Living \\
\hline High & hose & Word & Non-Living \\
\hline High & cage & Word & Non-Living \\
\hline High & robe & Word & Non-Living \\
\hline High & dough & Word & Non-Living \\
\hline High & thorn & Word & Non-Living \\
\hline High & mall & Word & Non-Living \\
\hline Low & beetle & Word & Living \\
\hline Low & $\operatorname{cod}$ & Word & Living \\
\hline Low & crow & Word & Living \\
\hline Low & hare & Word & Living \\
\hline Low & pony & Word & Living \\
\hline Low & cub & Word & Living \\
\hline Low & buffalo & Word & Living \\
\hline Low & flea & Word & Living \\
\hline Low & gopher & Word & Living \\
\hline Low & hawk & Word & Living \\
\hline Low & hornet & Word & Living \\
\hline Low & swan & Word & Living \\
\hline Low & toad & Word & Living \\
\hline Low & tortoise & Word & Living \\
\hline Low & mare & Word & Living \\
\hline Low & sage & Word & Living \\
\hline Low & plum & Word & Living \\
\hline Low & berry & Word & Living \\
\hline Low & parrot & Word & Living \\
\hline Low & pigeon & Word & Living \\
\hline Low & cricket & Word & Living \\
\hline Low & koala & Word & Living \\
\hline Low & primate & Word & Living \\
\hline Low & fig & Word & Living \\
\hline Low & moth & Word & Living \\
\hline
\end{tabular}




\begin{tabular}{lccc} 
Low & physician & Word & Living \\
Low & mice & Word & Living \\
Low & citizen & Word & Living \\
Low & maple & Word & Living \\
Low & daisy & Word & Living \\
Low & chamber & Word & Non-Living \\
Low & drill & Word & Non-Living \\
Low & encyclopedia & Word & Non-Living \\
Low & office & Word & Non-Living \\
Low & rail & Word & Non-Living \\
Low & cable & Word & Non-Living \\
Low & bolt & Word & Non-Living \\
Low & keys & Word & Non-Living \\
Low & museum & Word & Non-Living \\
Low & poster & Word & Non-Living \\
Low & supper & Word & Non-Living \\
Low & café & Word & Non-Living \\
Low & stool & Word & Non-Living \\
Low & shed & Word & Non-Living \\
Low & juice & Word & Non-Living \\
Low & zipper & Word & Non-Living \\
Low & emerald & Word & Non-Living \\
Low & pedal & Word & Non-Living \\
Low & telescope & Word & Non-Living \\
Low & linen & Word & Non-Living \\
Low & van & Word & Non-Living \\
Low & village & Word & Non-Living \\
Low & mattress & Word & Non-Living \\
Low & sleeve & Word & Non-Living \\
Low & jeep & Word & Non-Living \\
Low & cork & Word & Non-Living \\
Low & kite & Word & Non-Living \\
Low & pier & Word & Non-Living \\
Low & sack & Word & Non-Living \\
Low & drapes & Word & Non-Living \\
\hline
\end{tabular}




\section{Appendix B. List of words in the NSN experiment}

\begin{tabular}{|c|c|c|c|}
\hline \multirow{3}{*}{$\begin{array}{c}\text { NSN } \\
\text { Dimension }\end{array}$} & \multirow[b]{3}{*}{ Stimuli } & \multicolumn{2}{|c|}{ Decision Category } \\
\hline & & Lexical & Semantic \\
\hline & & Decision & Categorization \\
\hline High & celery & Word & Living \\
\hline High & chicken & Word & Living \\
\hline High & pine & Word & Living \\
\hline High & broccoli & Word & Living \\
\hline High & corn & Word & Living \\
\hline High & onions & Word & Living \\
\hline High & parsley & Word & Living \\
\hline High & pepper & Word & Living \\
\hline High & tomato & Word & Living \\
\hline High & beets & Word & Living \\
\hline High & grass & Word & Living \\
\hline High & lettuce & Word & Living \\
\hline High & oak & Word & Living \\
\hline High & owl & Word & Living \\
\hline High & sheep & Word & Living \\
\hline High & spinach & Word & Living \\
\hline High & cabbage & Word & Living \\
\hline High & cat & Word & Living \\
\hline High & cauliflower & Word & Living \\
\hline High & elk & Word & Living \\
\hline High & $\operatorname{dog}$ & Word & Living \\
\hline High & garlic & Word & Living \\
\hline High & horse & Word & Living \\
\hline High & lemon & Word & Living \\
\hline High & olive & Word & Living \\
\hline High & nightingale & Word & Living \\
\hline High & peas & Word & Living \\
\hline High & tree & Word & Living \\
\hline High & geese & Word & Living \\
\hline High & flower & Word & Living \\
\hline High & sofa & Word & Non-Living \\
\hline High & bench & Word & Non-Living \\
\hline High & cabinet & Word & Non-Living \\
\hline High & dress & Word & Non-Living \\
\hline High & jeans & Word & Non-Living \\
\hline High & cottage & Word & Non-Living \\
\hline High & couch & Word & Non-Living \\
\hline High & stone & Word & Non-Living \\
\hline High & sweater & Word & Non-Living \\
\hline
\end{tabular}




\begin{tabular}{|c|c|c|c|}
\hline High & vest & Word & Non-Living \\
\hline High & yolk & Word & Non-Living \\
\hline High & cake & Word & Non-Living \\
\hline High & chair & Word & Non-Living \\
\hline High & lamp & Word & Non-Living \\
\hline High & pipe & Word & Non-Living \\
\hline High & shoes & Word & Non-Living \\
\hline High & socks & Word & Non-Living \\
\hline High & veil & Word & Non-Living \\
\hline High & violin & Word & Non-Living \\
\hline High & bed & Word & Non-Living \\
\hline High & bottle & Word & Non-Living \\
\hline High & bridge & Word & Non-Living \\
\hline High & church & Word & Non-Living \\
\hline High & coat & Word & Non-Living \\
\hline High & bread & Word & Non-Living \\
\hline High & jacket & Word & Non-Living \\
\hline High & pistol & Word & Non-Living \\
\hline High & trousers & Word & Non-Living \\
\hline High & boots & Word & Non-Living \\
\hline High & mug & Word & Non-Living \\
\hline Low & shrimp & Word & Living \\
\hline Low & apple & Word & Living \\
\hline Low & leaf & Word & Living \\
\hline Low & pineapple & Word & Living \\
\hline Low & vine & Word & Living \\
\hline Low & turkey & Word & Living \\
\hline Low & hen & Word & Living \\
\hline Low & rat & Word & Living \\
\hline Low & fish & Word & Living \\
\hline Low & frog & Word & Living \\
\hline Low & lime & Word & Living \\
\hline Low & mandarin & Word & Living \\
\hline Low & moose & Word & Living \\
\hline Low & guy & Word & Living \\
\hline Low & ape & Word & Living \\
\hline Low & bean & Word & Living \\
\hline Low & pear & Word & Living \\
\hline Low & bouquet & Word & Living \\
\hline Low & plant & Word & Living \\
\hline Low & cherry & Word & Living \\
\hline Low & trout & Word & Living \\
\hline Low & walnut & Word & Living \\
\hline Low & whale & Word & Living \\
\hline Low & radish & Word & Living \\
\hline
\end{tabular}




\begin{tabular}{|c|c|c|c|}
\hline Low & groom & Word & Living \\
\hline Low & camel & Word & Living \\
\hline Low & coconut & Word & Living \\
\hline Low & lamb & Word & Living \\
\hline Low & cranberry & Word & Living \\
\hline Low & grape & Word & Living \\
\hline Low & airplane & Word & Non-Living \\
\hline Low & ambulance & Word & Non-Living \\
\hline Low & colander & Word & Non-Living \\
\hline Low & balloon & Word & Non-Living \\
\hline Low & bag & Word & Non-Living \\
\hline Low & letter & Word & Non-Living \\
\hline Low & sand & Word & Non-Living \\
\hline Low & canoe & Word & Non-Living \\
\hline Low & hat & Word & Non-Living \\
\hline Low & envelope & Word & Non-Living \\
\hline Low & hammer & Word & Non-Living \\
\hline Low & trombone & Word & Non-Living \\
\hline Low & kettle & Word & Non-Living \\
\hline Low & bus & Word & Non-Living \\
\hline Low & clarinet & Word & Non-Living \\
\hline Low & lantern & Word & Non-Living \\
\hline Low & pencil & Word & Non-Living \\
\hline Low & pin & Word & Non-Living \\
\hline Low & pillow & Word & Non-Living \\
\hline Low & anchor & Word & Non-Living \\
\hline Low & pearl & Word & Non-Living \\
\hline Low & blanket & Word & Non-Living \\
\hline Low & cookie & Word & Non-Living \\
\hline Low & paper & Word & Non-Living \\
\hline Low & harp & Word & Non-Living \\
\hline Low & pliers & Word & Non-Living \\
\hline Low & saxophone & Word & Non-Living \\
\hline Low & pie & Word & Non-Living \\
\hline Low & drum & Word & Non-Living \\
\hline Low & crowbar & Word & Non-Living \\
\hline
\end{tabular}

